\title{
Intraoperative ultrasound for identifying residual tumor during glioma surgery
}

\author{
Ultrassonografia intraoperatória para identificar tumor residual em ressecção de glioma
}

\section{Renata Motta Grubert ${ }^{1, a}$, Tiago Kojun Tibana ${ }^{1, b}$, Edson Marchiori ${ }^{2, c}$, Paulo Abdo do Seixo Kadri ${ }^{3, d}$, Thiago Franchi Nunes ${ }^{1, e}$}

1. Hospital Universitário Maria Aparecida Pedrossian da Universidade Federal de Mato Grosso do Sul (HUMAP-UFMS), Campo Grande, MS, Brazil. 2. Universidade Federal do Rio de Janeiro (UFRJ), Rio de Janeiro, RJ, Brazil. 3. Hospital Regional de Mato Grosso do Sul, Campo Grande, MS, Brazil. Correspondence: Dr. Thiago Franchi Nunes. Avenida Senador Filinto Müller, 355, Vila Ipiranga. Campo Grande, MS, Brazil, 79080-190. Email: thiagofranchinunes@gmail.com.

a. https://orcid.org/0000-0001-6713-2575; b. https://orcid.org/0000-0001-5930-1383; c. https://orcid.org/0000-0001-8797-7380; d. https://orcid.org/0000-0002-5075-8763; e. https://orcid.org/0000-0003-0006-3725.

Received 26 March 2018. Accepted after revision 11 June 2018.

\section{INTRODUCTION}

Several studies recently conducted in Brazil have emphasized the importance of imaging in the evaluation of brain tumors ${ }^{(1-3)}$. Glioma accounts for approximately $40 \%$ of central nervous system tumors and $70 \%$ of malignant brain tumors ${ }^{(4)}$. Its treatment protocols involve surgical resection, radiation therapy, and chemotherapy ${ }^{(5)}$. The primary goal of treatment is to increase survival through complete tumor resection. However, distinguishing the tumor from the surrounding brain tissue intraoperatively with a surgical microscope can be extremely challenging ${ }^{(5)}$.

Precise localization of the tumor and identification of its boundaries are crucial to improve surgical strategies. Real-time imaging with intraoperative ultrasound (IOUS) is a relatively simple and reproducible method that is widely used for tumor localization, monitoring of residual disease, aspiration biopsy guidance, and imaging of intracranial glioma blood flow ${ }^{(6,7)}$. Unlike IOUS, intraoperative magnetic resonance imaging and neuronavigation systems are costly and are limited in their capacity to detect glioma remnants because of the morphological and structural changes in the brain that occur after the opening of the skull and the meninges ${ }^{(8,9)}$. In recent years, the use of residual tumor detection devices has led to radical excisions and a consequent decrease in the rate of malignant degeneration, as well as an increase in mean and progression-free survival ${ }^{(5,8)}$.

IOUS has excellent diagnostic accuracy in identifying residual glioma, especially in patients with low-grade tumors, improving the prognosis and quality of life. IOUS is an effective, safe, inexpensive tool to optimize the extent of cerebral glioma resection ${ }^{(8)}$.

\section{PROCEDURE}

The decision regarding surgical resection should be made by a multidisciplinary team (interventional radiologist, neurosurgeon, and oncologist). Patient position during surgery will depend on the location of the tumor, as shown on previous tests, most commonly magnetic resonance imaging of the brain.

After craniotomy, a radiologist joins the team to provide ultrasound assistance. IOUS is performed with lowfrequency transducers (Figure 1A) for deeply located tumors or high-frequency transducers (Figure 1B) for cortico-subcortical lesions. The transducers are protected by sterilized plastic. The brain tissue is irrigated with saline solution to provide a better interface with the transducers and, as a consequence, higher image quality.

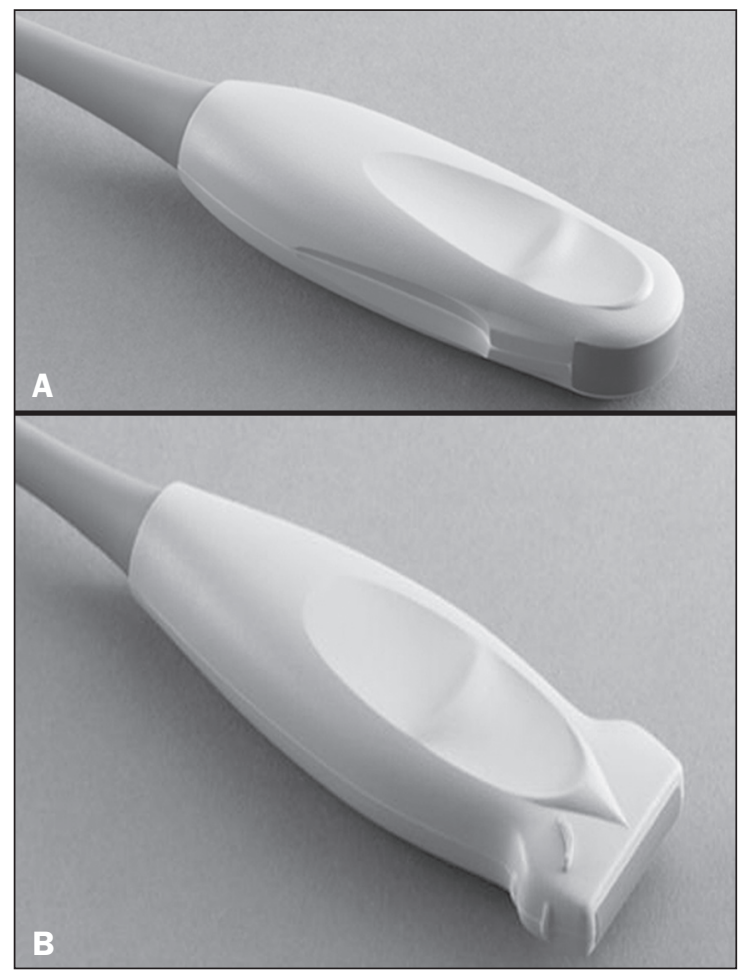

Figure 1. Transducers used in the procedure: convex low-frequency probe $(\mathbf{A})$ and linear high-frequency probe (B). 
Figure 2. A: IOUS performed with a linear high-frequency probe showing a primary brain tumor (glioma). B: Postoperative control image showing a porencephalic cavity (filled with saline solution) and no signs of residual lesion.

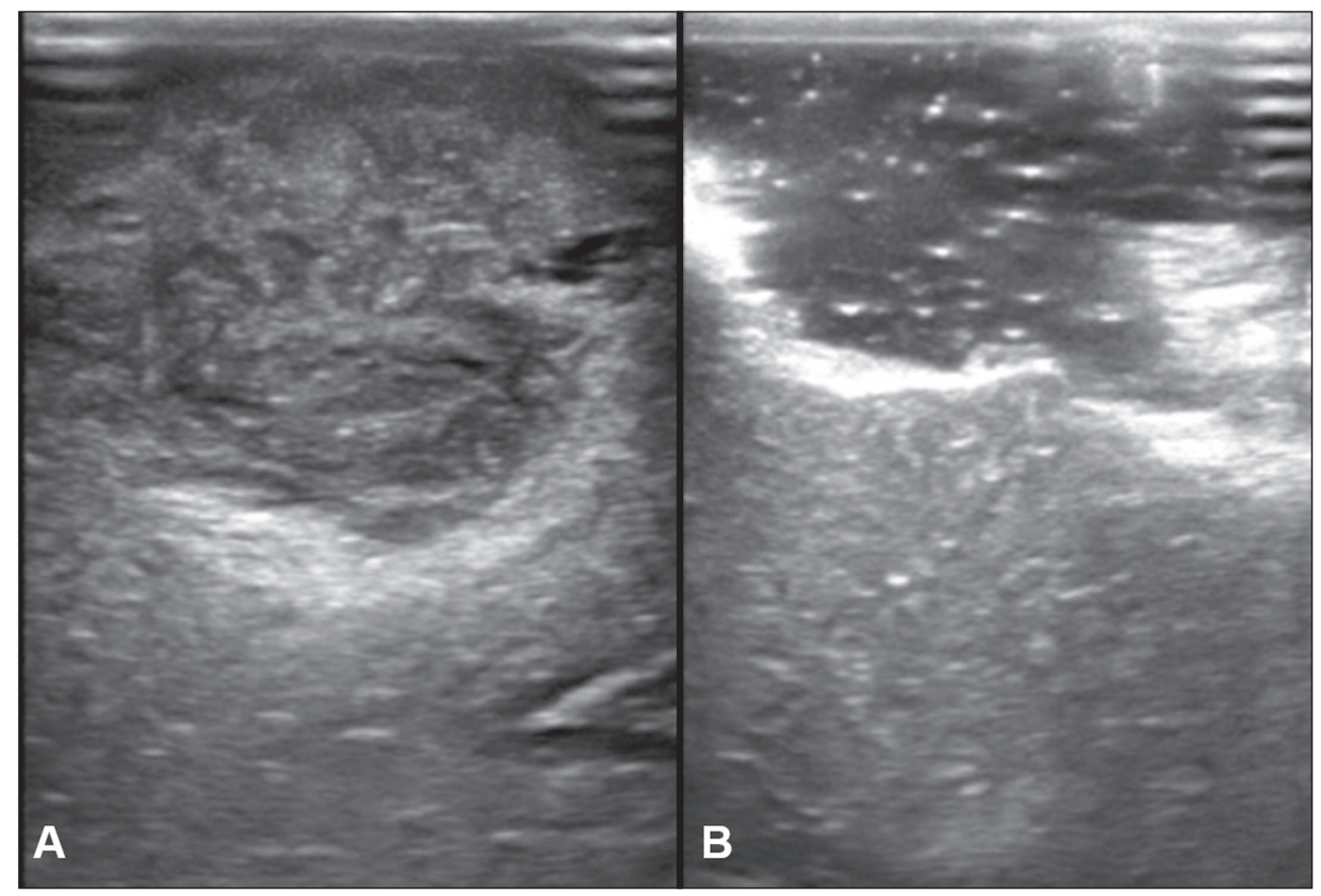

Before opening the dura mater, ultrasound scanning is performed to identify the texture of the tumor parenchyma, define its margins, determine its volume, and map its relationships with the adjacent tissues (Figure 2A). After resection, the cavity borders are reevaluated with IOUS to identify any residual tumor tissue or hematomas (Figure 2B). To avoid artifacts, all foreign bodies are removed from the resection cavity prior to image acquisition.

The ultrasound finding that characterizes residual tumor consists of an irregular and hyperechoic area, greater than $5 \mathrm{~mm}$ in thickness, extending to the brain tissue adjacent to the resection cavity. The use of IOUS does not lead to significant increases in total operative time or have any negative consequences for patients.

\section{REFERENCES}

1. Queiroz RM, Abud LG, Abud TG, et al. Burkitt-like lymphoma of the brain mimicking an intraventricular colloid cyst. Radiol Bras. 2017;50:413-4.
2. Abreu PP, Muniz BC, Ventura N, et al. Intraventricular ganglioglioma with dissemination of cerebrospinal fluid. Radiol Bras. 2018;51:272-3.

3. Niemeyer B, Muniz BC, Ventura N, et al. Papillary tumor of the pineal region accompanied by Parinaud's syndrome: magnetic resonance imaging findings. Radiol Bras. 2018;51:202-4.

4. Ostrom QT, Gittleman H, Liao P, et al. CBTRUS statistical report: primary brain and central nervous system tumors diagnosed in the United States in 2007-2011. Neuro Oncol. 2014;16 Suppl 4:iv1-63.

5. Erdoğan N, Tucer B, Mavili E, et al. Ultrasound guidance in intracranial tumor resection: correlation with postoperative magnetic resonance findings. Acta Radiol. 2005;46:743-9.

6. Regelsberger J, Lohmann F, Helmke K, et al. Ultrasound-guided surgery of deep seated brain lesions. Eur J Ultrasound. 2000;12:11521.

7. Sosna J, Barth MM, Kruskal JB, et al. Intraoperative sonography for neurosurgery. J Ultrasound Med. 2005;24:1671-82.

8. Zhang G, Li Z, Si D, et al. Diagnostic ability of intraoperative ultrasound for identifying tumor residual in glioma surgery operation. Oncotarget. 2017;8:73105-14.

9. Gerganov VM, Samii A, Akbarian A, et al. Reliability of intraoperative high-resolution 2D ultrasound as an alternative to high-field strength MR imaging for tumor resection control: a prospective comparative study. J Neurosurg. 2009; 111 1:512-9.

\section{$(\infty)) \mathrm{EY}$}

